American Journal of Pharmaceutical Education 2017; 81 (5) Article 92.

\title{
RESEARCH
}

\section{Dietary Supplement Use, Knowledge, and Perceptions Among Student Pharmacists}

\author{
David R. Axon, MPharm, Janka Vanova, PharmD, Courtney Edel, PharmD, Marion Slack, PhD \\ University of Arizona College of Pharmacy, Tucson, Arizona
}

Submitted May 6, 2016; accepted August 29, 2016; published June 2017.

Objective. To compare dietary supplement use between student pharmacists and the general population, and assess knowledge, attitudes toward use, and dietary supplement effectiveness; and to explore how student pharmacists view their education on dietary supplements.

Methods. Paper questionnaires administered to student pharmacists collected data about their use, knowledge, and attitudes of dietary supplements. Use was compared to the 2007 National Health Interview survey findings.

Results. Of 179 students who responded, $52 \%$ had used at least one dietary supplement in their lifetime versus $25 \%$ in the general population. Students perceived supplement label information as unhelpful, research into supplements inadequate, and supplements non-essential to health. Students thought supplement knowledge was important but their education was inadequate.

Conclusion. Dietary supplement use was higher in this sample of student pharmacists than the general population. Student pharmacists had limited knowledge and need more education on dietary supplements.

Keywords: dietary supplements use, dietary supplements knowledge, dietary supplements education

\section{INTRODUCTION}

The Dietary Supplement Health and Education Act of 1994 assured consumer access to a wide range of dietary supplements. ${ }^{1}$ A dietary supplement is defined by the Food and Drug Administration (FDA) as "a product intended for ingestion that contains a "dietary ingredient" intended to add further nutritional value to (supplement) the diet." A "dietary ingredient" is defined as "one, or any combination, of the following substances: a vitamin, a mineral, an herb or other botanical, an amino acid, a dietary substance for use by people to supplement the diet by increasing the total dietary intake, a concentrate, metabolite, constituent or extract." 2 Dietary supplements are available in many different formulations and are used to increase dietary intake of essential nutrients and reduce disease risk. ${ }^{2}$ A variety of dietary supplements are now available in the United States including single-ingredient products and various combinations of vitamins, minerals, botanicals and other constituents. ${ }^{1}$ There is considerable media attention on supplements, including advertisement, informational articles, and studies reporting associations

Corresponding Author: David Rhys Axon, Department of Pharmacy Practice and Science, University of Arizona College of Pharmacy, 1295 North Martin Ave., Tucson, AZ 85721. Tel: 520-373-9381. E-mail: axon@pharmacy. arizona.edu with health conditions. ${ }^{1}$ Supplement sales in the United States reached $\$ 28$ billion in 2010, and are forecast to reach $\$ 36$ billion by 2017 . $^{3}$

Dietary and herbal supplement use is common and rapidly rising throughout the US. ${ }^{1,4-6}$ According to data from the 2007 National Health Interview Survey, 25\% of adults in the US had ever used (ie, used a dietary supplement sometime in their life) a dietary or herbal supplement. ${ }^{7} \mathrm{Di}$ etary supplement use is associated with education and race/ ethnicity. ${ }^{6}$ The most commonly used dietary supplements include multivitamins/multiminerals, vitamin $\mathrm{C}$, vitamin $\mathrm{E}$, and calcium. ${ }^{1}$ The top non-multivitamin/non-multimineral dietary supplements include fish oil, omega-3/DHA, glucosamine, echinacea, flaxseed oil, chondroitin and ginseng. ${ }^{7}$

Manufacturers are not required to demonstrate the safety and efficacy of herbal supplements to the FDA. ${ }^{8}$ Therefore it is essential that consumers have good knowledge about dietary and herbal supplements so that they are used safely and effectively. Individuals with higher education and a high level of dietary supplement knowledge, such as student pharmacists, are likely to be more selective with their use of dietary or herbal supplements than the general population. Comparing use of dietary supplements between student pharmacists and the general population should provide insight into the influence of knowledge on dietary and herbal supplement use. 


\section{American Journal of Pharmaceutical Education 2017; 81 (5) Article 92.}

Given the widespread use of dietary and herbal supplements, it is important for pharmacists to be wellinformed about these products. However, it has been noted that community pharmacists have poor knowledge of dietary and herbal supplements ${ }^{9,10}$ and are not proactively inquiring about their patients' dietary and herbal supplement use. ${ }^{11}$ Community pharmacists are dissatisfied with the quality of information available on dietary and herbal supplements, and thus rarely use the reference sources available to them. ${ }^{12-14}$ Therefore, it is vital that pharmacists receive adequate education about dietary and herbal supplements so that they have the ability to counsel patients on their use and to identify potential interactions that may cause harm to the patient.

This study's two primary objectives were to compare the personal use, perceptions, and knowledge of dietary and herbal supplements among student pharmacists and the general population; and to explore how student pharmacists view their education on dietary and herbal supplements.

\section{METHODS}

This was a descriptive study approved by the Human Subjects Protection Program. Student pharmacists received didactic teaching of dietary and herbal supplements in the spring semester of their second year in the program. This knowledge was then developed and applied during their Introductory Pharmacy Practice Experiences (IPPE) and Advanced Pharmacy Practice Experiences (APPE).

Participants included first-, second- and third-year (P1, P2, and P3) student pharmacists from the class years 2016-2018 attending a single college of pharmacy in the United States and the population surveyed in the 2007 National Health Interview Survey. Students who did not attend class on the day the questionnaire was administered were excluded from the study.

A 29-item questionnaire was created to obtain data from the students using features from four previous studies and questionnaires ${ }^{6-8,15-16}$ including the $\mathrm{Na}$ tional Health Interview Survey (NHIS): Adult Alternative Health/Complementary and Alternative Medicine from May 2008.

The first nine questions asked students about their dietary or herbal supplement use, which included selecting any supplement they have taken from a common list of supplements, reporting the reasons they took the supplement and the condition they were aiming to treat, describing any side effects experienced and how they were resolved, and whether or not they would recommend dietary or herbal supplements to friends or family.
The next six questions tested their knowledge of herbal supplements, including the information sources they used to inform themselves about dietary and herbal supplements, the role of the FDA with respect to supplements, and matching adverse reactions and health benefits associated with each supplement.

The following five questions assessed their attitudes toward the use of dietary or herbal supplements, which included exploring how they view the label information, the amount of research they conducted, health benefits, and importance of knowledge and education offered on dietary and herbal supplements. Responses to these five questions were provided on a numerical rating scale from 0 to 5 , where 0 indicated the lowest score and 5 the highest.

The final nine questions collected students' demographic and work experience information, which included age, gender, race, ethnicity, year in pharmacy school, work experience setting, selling or counseling patients on dietary or herbal supplements, and the main reason they do or do not take dietary or herbal supplements.

The questionnaire was administered to student pharmacists before a regularly scheduled class in fall 2014. A recruitment script containing information about the survey and privacy rights was read to all participants before data collection began, and students were advised that they were not obligated to participate. Questionnaires were collected and data were inputted into a Microsoft Excel (version 14; Redmond, WA) spreadsheet according to the codebook for analysis.

To compare use of dietary and herbal supplements in the general population with use by student pharmacists, the proportion of the general population that used dietary or herbal supplements was calculated from reports of the 2007 NHIS survey, and the proportion of student pharmacists who used dietary or herbal supplements was calculated from the questionnaires. Students were considered ever-users of dietary supplements if they indicated that they had ever used at least one of the listed supplements. These proportions were then compared using the chisquare test. To compare students' knowledge between different classes, the mean (and standard deviation) number of correct knowledge items (four items) for students in each class (P1, P2, and P3) was calculated. Means were reported for the total knowledge score. ANOVA was conducted first, then a Bonferroni post-hoc test compared P1 to $\mathrm{P} 2$ and $\mathrm{P} 3$, and compared $\mathrm{P} 2$ and $\mathrm{P} 3$. To compare student attitudes toward supplement use between students who do and do not use supplements, respondents were grouped into "users" and "non-users" according to the responses on a question asking about dietary supplement use. The median (and range) attitude scores for these five 


\section{American Journal of Pharmaceutical Education 2017; 81 (5) Article 92.}

items were calculated for each group (users vs. nonusers), and compared using a Kruskal-Wallis test. Descriptive and demographic variables (reason for using supplement, medical condition used for, side effects, seeing medical practitioner or going to emergency room for side effects, recommend to family or patients, reasons for not using, sources of information, age, gender, work site, sell supplements, counseling on supplements, race, and ethnicity) were analyzed by calculating frequencies and percentages for categorical variables. The a priori alpha level was .05.

Finally, logistic regression was performed using SPSS (v23; Armonk, NY) ${ }^{17}$ to identify factors associated with dietary or herbal supplement use among student pharmacists. The dependent variable was "ever use of herbal supplements" (calculated by grouping respondents as "users" if they had ever used one or more of the listed supplements or "non-users" if they had not). Fish oil/ omega-3 and psyllium/fiber were not included in the logistic regression model due to their common use (the nonuser group would have been very small if they were included), in order to differentiate between "users" and "non-users." Independent variables included gender, total knowledge score (calculated by summing the knowledge items), use of government sources to obtain information about herbal supplements, sell supplements, age (grouped into $18-25$ or 26 and above), recommend herbal supplements to friends or family, and recommend herbal supplements to patients.

\section{RESULTS}

Demographic characteristics of study participants are shown in Table 1. A total of 179 students returned questionnaires with usable data for a response rate of $60 \%$. P2 and P3 students were significantly more likely to have gained experience of an in-patient hospital setting than P1 students $(p=.04)$. P3 students were also more likely to have gained experience at a long-term care setting $(p=.01)$. There were no significant differences between years for the remaining pharmacy settings. A significantly larger portion of P3 students had counseled patients on dietary supplements (63\%) than P2 (48\%) and P1 $(12 \%)$ students $(p<.01)$. There was no significant difference between classes based on age $(p=.60)$, gender $(p=.19)$, race $(p=.87)$ or ethnicity $(p=.59)$.

The ever use of dietary supplements by students is shown in Table 2. There was no significant difference in the use of listed dietary supplements among P1, P2, and P3 students. Almost half (46\%) of the students had used fish oil or omega-3 fatty acids. The second most frequently used supplement was fiber or psyllium, used by $18 \%$ of the students. Use of all other listed supplements
Table 1. Demographic Characteristics of Study Participants

\begin{tabular}{|c|c|c|c|c|}
\hline Characteristic & $\begin{array}{c}\mathbf{P 1}^{\mathbf{a}} \\
\mathbf{N}(\%)\end{array}$ & $\begin{array}{c}\text { P2 } \\
\text { N }(\%)\end{array}$ & $\begin{array}{c}\text { P3 } \\
\text { N }(\%)\end{array}$ & $p$ value \\
\hline $\mathrm{N}$ & 53 & 71 & 47 & \\
\hline \multicolumn{5}{|l|}{ Gender } \\
\hline Male & $22(42)$ & $21(30)$ & $21(45)$ & .19 \\
\hline Age & & & & .60 \\
\hline $18-25$ & $41(77)$ & $57(80)$ & $35(75)$ & \\
\hline $26-35$ & $12(23)$ & $12(17)$ & $10(21)$ & \\
\hline$>36$ & $0(0)$ & $2(3)$ & $2(4)$ & \\
\hline \multicolumn{5}{|c|}{ Pharmacy setting worked in } \\
\hline Community (chain) & $30(53)$ & $41(57)$ & $30(64)$ & .51 \\
\hline Long-term care & $0(0)$ & $1(1)$ & $5(11)$ & $.01^{\mathrm{b}}$ \\
\hline $\begin{array}{l}\text { Community } \\
\text { (independent) }\end{array}$ & $7(12)$ & $10(14)$ & $6(13)$ & .96 \\
\hline Hospital (out-patient) & $7(12)$ & $10(14)$ & $4(9)$ & .67 \\
\hline Hospital (in-patient) & $4(7)$ & $12(17)$ & $12(26)$ & $.04^{\mathrm{c}}$ \\
\hline Managed Care & $4(7)$ & $6(8)$ & $3(6)$ & .92 \\
\hline \multicolumn{5}{|c|}{ Pharmacy sell supplements } \\
\hline Yes & $14(29)$ & $17(26)$ & $10(22)$ & .34 \\
\hline No & $32(67)$ & $44(67)$ & $35(78)$ & \\
\hline Don't know & $2(4)$ & $5(8)$ & $0(0)$ & \\
\hline \multicolumn{5}{|l|}{ Counseled on supplements } \\
\hline Yes & $6(12)$ & $31(48)$ & $20(63)$ & $<.01^{\mathrm{d}}$ \\
\hline \multicolumn{5}{|l|}{ Race } \\
\hline White & $31(61)$ & $38(58)$ & $25(56)$ & .87 \\
\hline \multicolumn{5}{|l|}{ Ethnicity } \\
\hline Hispanic & $6(12)$ & $11(17)$ & $5(11)$ & .59 \\
\hline
\end{tabular}

${ }^{\mathrm{a}} \mathrm{P} 1=$ first professional year, $\mathrm{P} 2=$ second professional year, $\mathrm{P} 3=$ third professional year

${ }^{\mathrm{b}}$ Third-year student pharmacists were significantly more likely to have gained experience at a long-term care setting $(p=.01)$ than firstor second-year student pharmacists

${ }^{\mathrm{c}}$ Second- and third-year students were significantly more likely to have gained experience at an in-patient hospital setting than first-year students $(p=.04)$

${ }^{\mathrm{d}}$ A significantly larger portion of third-year students had counseled patients on dietary supplements than first- and second-year students $(p<.01)$

was less than $15 \%$, which indicates that use of most dietary supplements among students is low. Ever use of any dietary supplement $(52 \%)$ was higher in this sample of students than in the general population $(25 \%)$. This difference may be explained by the high use of fish oil/ omega-3 and fiber/psyllium. Almost half of students $(46 \%)$ indicated they would recommend dietary and herbal supplements to their friends and family, and $41 \%$ reported they would recommend dietary and herbal supplements to their patients.

The most common reason students used dietary or herbal supplements was to prevent disease (24\%). The next most common reasons were to improve physical performance (19\%), improve immune function (16\%), and 


\section{American Journal of Pharmaceutical Education 2017; 81 (5) Article 92.}

Table 2. Ever Use of Dietary Supplements by Student Pharmacists $^{\mathrm{a}}$

\begin{tabular}{lcccc}
\hline & P1 & P2 & P3 & \\
Supplement & $\mathbf{N}(\%)$ & $\mathbf{N}(\mathbf{\%})$ & $\mathbf{N}(\%)$ & $\boldsymbol{p}$ value \\
\hline $\mathrm{N}$ & 57 & 74 & 48 & \\
Ever use of any & $29(51)$ & $42(57)$ & $22(46)$ & \\
$\quad$ supplement & & & & \\
Fish Oil/ Omega-3 & $32(56)$ & $34(46)$ & $16(33)$ & .36 \\
Glucosamine & $7(12)$ & $8(11)$ & $6(13)$ & .95 \\
Echinacea & $2(5)$ & $9(12)$ & $4(8)$ & .38 \\
Flaxseed oil/caps & $8(14)$ & $11(15)$ & $4(8)$ & .55 \\
Chondroitin & $6(11)$ & $4(5)$ & $6(13)$ & .36 \\
Ginseng & $7(12)$ & $12(16)$ & $7(15)$ & .82 \\
Garlic supplements & $3(5)$ & $4(5)$ & $3(6)$ & .97 \\
Ginkgo Biloba & $4(7)$ & $7(10)$ & $2(4)$ & .54 \\
Coenzyme Q10 & $3(5)$ & $8(11)$ & $3(6)$ & .45 \\
Fiber/Psyllium & $11(19)$ & $14(19)$ & $7(15)$ & .78 \\
Saw Palmetto & $1(2)$ & $3(4)$ & $2(4)$ & .72 \\
Cranberry pills & $6(11)$ & $10(14)$ & $3(6)$ & .45 \\
Green tea pills & $5(9)$ & $6(8)$ & $2(4)$ & .62 \\
Soy/isoflavones & $2(4)$ & $6(8)$ & $2(4)$ & .46 \\
St. John's Wort & $2(4)$ & $4(5)$ & $3(6)$ & .80 \\
\hline
\end{tabular}

${ }^{a}$ Ever use of supplements is defined as whether or not students used any of the listed supplements. Students were considered ever-users if they indicated they used at least one of the listed supplements

because they were recommended by family or friends $(16 \%)$. Few students indicated that they used dietary supplements to treat disease ( $9 \%$ ), improve sports performance $(9 \%)$, improve mental ability or memory $(8 \%)$, because a health care provider recommended them $(7 \%)$, to improve sexual performance $(1 \%)$, because medical treatment was no help (1\%) or too expensive (1\%). No one indicated that they used dietary supplements because prescription or over-the-counter drugs were too expensive. The reason "to improve mental ability or memory" was significantly different based on year in the pharmacy program $(p=.05)$. All other reasons were insignificant.
Attitudes of student pharmacists toward the use of dietary and herbal supplements are shown in Table 3. Students generally did not think that information provided on labels helped them understand if it is the right supplement to use. P3 students' rating on label usefulness was significantly lower in comparison with P1 students $(p=.03)$. Students typically rated research on dietary supplements as inadequate. However, P1 students thought research was more adequate $(p<.01)$ compared to $\mathrm{P} 3$ students. Students from all three years reported that dietary and herbal supplements were not essential for health with a median score of 2 . Knowledge about dietary and herbal supplements was considered very important (median score 5). Students agreed that the amount of education offered on dietary supplements at the College of Pharmacy was inadequate, however P2 students considered the amount of education to be less adequate than $\mathrm{P} 1$ and $\mathrm{P} 3$ students $(p<.01)$.

Students who used a dietary supplement to treat a medical condition mostly indicated that the treatment was effective. Commonly used dietary supplements to treat listed medical conditions were glucosamine/chondroitin, fiber/psyllium, echinacea, tiger balm, and omega-3/fish oil. Students also used dietary and herbal supplements to treat atopic dermatitis, urinary tract infections, to boost the immune system and to improve heart health. Four of the students who used dietary and herbal supplements to treat medical conditions experienced side effects from their use; these were increased bleeding during surgery (fish oil), auditory hallucinations (yohimbe), tachycardia (ginseng), severe abdominal pain (flax seed) and opioidlike side effects (kratom). Two of these students saw a medical practitioner in response to experiencing side effects.

Students who had never used dietary or herbal supplements were asked to indicate the reason they did not use them. The most common reason for not using dietary and herbal supplements was they thought they did not

Table 3. Student Pharmacists' Attitudes Toward Use of Dietary Supplements ${ }^{\mathrm{a}}$

\begin{tabular}{|c|c|c|c|c|}
\hline Attitude & $\begin{array}{c}\text { P1 } \\
\text { Median (range) }\end{array}$ & $\begin{array}{c}\text { P2 } \\
\text { Median (range) }\end{array}$ & $\begin{array}{c}\text { P3 } \\
\text { Median (range) }\end{array}$ & $p$ value \\
\hline$\overline{\mathrm{N}}$ & 52 & 71 & 47 & \\
\hline Adequate amount of research into supplements & $2(0-5)$ & $2(0-4)$ & $1(0-4)$ & $<.01^{\mathrm{c}}$ \\
\hline Supplements are essential for health & $2(0-5)$ & $2(0-4)$ & $2(0-4)$ & 67 \\
\hline Knowledge of supplements is important & $5(1.5)$ & $5(1-5)$ & $5(1-5)$ & .94 \\
\hline
\end{tabular}

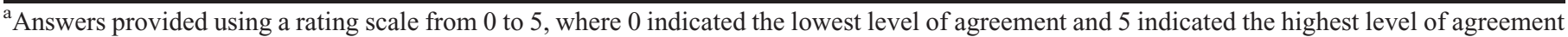

'Third-year students' rating on label usefulness was significantly lower in comparison with the first-year students $(p=.03)$

${ }^{c}$ First-year students thought research was more adequate $(p<.01)$ compared to third-year students

${ }^{\mathrm{d}}$ Second-year students considered the amount of education to be less adequate than first- and third-year students $(p<.01)$ 


\section{American Journal of Pharmaceutical Education 2017; 81 (5) Article 92.}

need it $(56,31 \%)$. Forty-three students $(24 \%)$ did not use dietary and herbal supplements because they did not believe in it, 32 students (18\%) had no reason for using dietary and herbal supplements and 29 students (16\%) had never even thought of using supplements. Twenty-seven students $(15 \%)$ indicated they did not use dietary and herbal supplements because they had not been shown to be medically effective. Twenty-three students (13\%) had never heard of dietary and herbal supplements or did not know much about the subject. One student $(0.6 \%)$ indicated that dietary and herbal supplements are not safe to use.

Students had limited knowledge about use of dietary and herbal supplements. The average score for side effects and reasons to use dietary supplements was $6.2(43 \%$; $\mathrm{SD}=2.9)$. Most students $(90 \%)$ recognized that the FDA does not require dietary supplements to be proven to be safe and effective before marketing. However, only $34 \%$ of students recognized that the FDA was required to monitor the safety of dietary supplements once they are on the market.

When deciding whether or not to use dietary and herbal supplements, students most often consulted journals and professional newsletters $(92,51 \%)$. Other sources of information for dietary and herbal supplements that students used were databases $(85,48 \%)$, labels on product containers $(82,46 \%)$ and lecture material from classes (76, 43\%). Forty-one students (23\%) used reports of clinical randomized trials as a source of information. The same number of students $(33,18 \%)$ used educational programs, and reports of systematic reviews or meta-analyses. Only a small number of students $(22,12 \%)$ referred to textbooks. The least likely source students consulted for information on dietary supplements was health food stores $(13,7 \%)$. Almost half of the students $(86,49 \%)$ used government sources to obtain information about dietary and herbal supplements.

Only two independent variables in the logistic regression were statistically associated with dietary supplement use among students: "total knowledge score" $(p=.02)$ and "recommend herbal supplements to friends or family" ( $p=.04)$. The strongest predictor of reporting herbal supplement use was "recommend herbal supplements to friends or family" (odds ratio $=3.45$ ), which indicated that respondents who recommended herbal supplements to friends or family were nearly 3.5 times more likely to have used herbal supplements than those who did not recommend herbal supplements to friends or family. Total knowledge score (odds ratio $=1.18$ ) indicated that having more knowledge of dietary supplements was associated with slightly more use.

\section{DISCUSSION}

The two most important findings of this study were that more students $(52 \%)$ than the general population
(25\%) reported ever using at least one dietary supplement, and students considered their education on dietary supplements to be inadequate. The primary reasons that students used dietary supplements was to prevent disease, improve physical performance, improve immune function, or because family or friends had recommended the product. A few students ( $2 \%$ ) attributed adverse effects to the dietary supplement they had used.

Although students considered dietary supplements not essential for health, student use of at least one dietary supplement was greater than that of the general public. This relates to the findings of previous studies that found high prevalence and widespread use of herbal supplements among pharmacists. ${ }^{14,18}$ However, only two products-fiber/psyllium and fish oil/omega-3-were used by more than $20 \%$ of the respondents. Use of all other products was less than $20 \%$. Although the college is located in a multicultural environment, the student cohort is not a representative sample. Therefore this greater use of supplements among students cannot be attributed to particular cultural influences. No student indicated that they used dietary supplements because prescription or over-thecounter medications were too expensive or ineffective. Variations in terminology and studies that include complementary and alternative medicine in addition to dietary supplements make it difficult to compare students' use of dietary supplements. An Australian study found that 93.7\% of Australian student pharmacists in their sample had used "complementary medicines." 19 In Minnesota, $20 \%$ of P4 students had used "herbal medicines" and $35 \%$ had used "nutritional supplements." ${ }^{20}$ Thus, the $52 \%$ of students who had used at least one dietary supplement at least once, seems consistent with the findings of other studies that a substantial portion of student pharmacists use at least some alternative or complementary therapies. However, this is higher than the general population use of $25 \%$ who had ever used a dietary or herbal supplement.

The second important finding relates to the education student pharmacists receive. Student pharmacists reported that having knowledge of dietary supplements was important, but considered their education on dietary supplements to be insufficient. Similar findings have been reported in other studies. ${ }^{21-22}$ A study of pharmacists in Missouri found over half of them received questions from patients about natural products, but only $2.4 \%$ were able to answer them. ${ }^{23}$ Another study reported health care professionals had insufficient knowledge about adverse effects of dietary and herbal supplements, and did not routinely communicate with patients about dietary and herbal supplements. ${ }^{24}$ Since dietary and herbal supplements are taught in the spring semester of the second year, 


\section{American Journal of Pharmaceutical Education 2017; 81 (5) Article 92.}

and the survey was administered in the fall, only P3 students would have been taught about dietary and herbal supplements when responding to the survey. Students have the opportunity to apply the knowledge they have learned in class during IPPEs; however, P1 or P2 students who have not received any formal instruction on dietary and herbal supplements may not have adequate knowledge to correctly identify interactions or provide advice and counseling to patients. This finding has important implications for pharmacy education, suggesting that there is a need to improve the education student pharmacists receive about dietary and herbal supplements so that they are better able to deal with pharmaceutical issues arising from dietary and herbal supplements when they enter service as a registered pharmacist.

Interactions between prescription medications and dietary supplements are a huge concern. Research using NHANES data found $34.3 \%$ of all adults in the US and $47.3 \%$ of patients with a diagnosed medical condition take both a prescription medication and dietary supplement together. ${ }^{25}$ Another nationally representative survey of older adults in the US found 52\% took a dietary supplement with prescription medication. ${ }^{15}$ Furthermore, many supplements contain pharmaceutical contaminants. The FDA website warns that health fraud drug products can have serious or fatal consequences, and publishes an extensive list of public notifications describing contaminated supplements. ${ }^{26}$ For example, a dietary supplement for weight loss contaminated with a stimulant resulted in consumers being hospitalized with serious health conditions. ${ }^{27}$ These studies clearly highlight the need for pharmacists to have good knowledge of drug-supplement interactions, so that they are able to identify interactions and offer the best advice possible to patients.

There has long been a call to increase student pharmacists' education in dietary and herbal supplements. ${ }^{14,24,28-29}$ Funding has been made available in the past to both medical and nursing schools to teach complementary and alternative medicines in the curriculum, which brought benefits such as greater collaboration among faculty and institutions, but challenges such as a lack of qualified faculty and a crowded and changing curricula remain. ${ }^{30}$ Such benefits and challenges may be similar in the pharmacy school environment. A white paper published by the American College of Clinical Pharmacy recommended that natural products, such as dietary and herbal supplements, should be included in the curriculum of pharmacy schools. ${ }^{31}$

The Accreditation Council for Pharmacy Education (ACPE) has since included dietary supplements as a required element of the didactic pharmacy curriculum. ${ }^{32}$ Several pharmacy schools have attempted to improve dietary supplement teaching; dedicated classes using active learning exercises have been found to improve students' dietary supplement knowledge and emphasized the importance of pharmacists' dietary supplement knowledge in clinical practice. ${ }^{33-34}$ Our institution provided the results of this study to the curriculum committee, with the intention that changes will be made in the forthcoming curriculum review. Given that student pharmacists' views of dietary and herbal supplements are dependent upon the education they receive, ${ }^{35}$ it is important to educate future pharmacists appropriately so that they can offer holistic advice to patients in the future. A survey of pharmacists at a national meeting found pharmacists typically self-educated themselves about dietary supplements, using online references, other practitioners, and word of mouth. ${ }^{36}$ Another study revealed that only $12.5 \%$ of pharmacists learned about natural products in pharmacy school, ${ }^{23}$ suggesting there may be a need for a continuing education program for pharmacists who received no or inadequate education about dietary supplements while in pharmacy school. An instrument has been developed and tested to assess pharmacists' and student pharmacists' ability to counsel patients on dietary and herbal supplements. ${ }^{37}$ The authors also suggest this instrument to assess student pharmacists' dietary supplement counseling could be used to examine student pharmacists' competencies for dietary and herbal supplements. ${ }^{37}$

Since there appears to have been improvements in natural product teaching across the United States and a formal requirement for it to be taught at pharmacy schools, it would be interesting to survey pharmacists who have recently graduated to investigate whether or not they think they have an adequate knowledge of dietary supplements, since they should have received at least some education on the topic in pharmacy school. In addition, a survey such as the one administered in this study could be administered to student pharmacists at other US pharmacy schools to identify current perceptions of dietary and herbal supplements teaching. The findings of our study suggest that although student pharmacists receive education on dietary supplements, it is deemed insufficient. It would be useful to know if this is a nationwide or local perception. Therefore, it may also be interesting to investigate how information about dietary and herbal supplements was taught, to identify methods that appear to work and make recommendations to improving the pharmacy curriculum with respect to dietary supplement teaching.

A limitation of this study was that it included only the students who were present in class at the time when the questionnaire was administered. P4 students were taking advanced pharmacy practice rotations so were not 


\section{American Journal of Pharmaceutical Education 2017; 81 (5) Article 92.}

included in the study. Their potentially enhanced knowledge and experience over students in the first three years may have impacted the results. Also, this study only examined student pharmacists from one college of pharmacy; thus, the results may not be generalizable to all student pharmacists across the US, or the general population.

\section{CONCLUSION}

Ever use of dietary supplements in this sample of student pharmacists was higher than in the general population ( $52 \%$ vs. $25 \%)$. Student pharmacists perceived dietary supplements as not essential for health, the label information as unhelpful, and research as inadequate. Students thought dietary or herbal supplement knowledge was important, but their knowledge was limited. The results of this study suggest that more education on dietary and herbal supplements is necessary so that future pharmacists are able to provide adequate advice to patients about their supplement use.

\section{REFERENCES}

1. Radimer K, Bindewald B, Hughes J et al. Dietary supplement use by US adults: data from the National Health and Nutrition Examination Survey, 1999-2000. Am J Epidemiol. 2004; 160(4):339-349.

2. U.S. Food and Drug Administration (FDA). What is a dietary supplement? http:/www.fda.gov/aboutfda/transparency/basics/ ucm195635.htm. Accessed January 18, 2016.

3. Statista - The Statistics Portal. Retail sales of vitamins \& nutritional supplements in the United States from 2000 to 2017 (in billion US dollars). http://www.statista.com/statistics/235801/ retail-sales-of-vitamins-and-nutritional-supplements-in-the-us/. Accessed July 16, 2016

4. Barnes PM, Powell-Griner E, McFann K, Nahin RL.

Complementary and alternative medicine use among adults: United States, 2002. Adv Data. 2004;27(343):1-19.

5. Chauhan B, Kumar G, Kalam N, Ansari SH. Current concepts and prospects of herbal nutraceutical: a review. J Adv Pharm Technol Res. 2013;4(1):4-8.

6 . Kennedy J. Herb and supplement use in the US adult population. Clin Ther. 2005;27(11):1847-1858.

7. Wu CH, Wang CC, Kennedy J. Changes in herb and dietary supplement use in the US adult population: a comparison of the 2002 and 2007 National Health Interview Surveys. Clin Ther. 2011; 33(11):1749-1758.

8. US Food and Drug Administration. FDA 101: dietary supplements. FDA Consumer Health Information. 2008.

9. Coon SA, Stevens VW, Brown JE, et al. Comparison of dietary supplement product knowledge and confidence between pharmacists and health food store employees. J Am Pharm Assoc. 2015; 55(2):161-168.

10. Waddington F, Naunton M, Kyle G, et al. A systematic review of community pharmacist therapeutic knowledge of dietary

supplements. Int J Clin Pharm. 2015;37(3):439-446.

11. Brown CM, Barner JC, Shah S. Community pharmacists' actions when patients use complementary and alternative therapies with medications. J Am Pharm Assoc. 2005;45(1):41-47.
12. Nathan JP, Cicero LA, Koumis T, et al. Availability of and attitudes toward resources on alternative medicine products in the community pharmacy setting. J Am Pharm Assoc. 2005;45(6):734-739. 13. Zeolla MM, Cerulli J. Use of and familiarity with dietary supplement information references by practicing pharmacists. $J \mathrm{Am}$ Pharm Assoc. 2008;48(3):401-404.

14. Koh HL, Teo HH, Ng HL. Pharmacists' patterns of use, knowledge, and attitudes toward complementary and alternative medicine. J Altern Complement Med. 2003;9(1):51-63.

15. Qato DM, Alexander GC, Conti RM, et al. Use of prescription and over-the-counter medications and dietary supplements among older adults in the United States. JAMA. 2008;300(24):2867-78. 16. National Center for Health Statistics. National Health Interview Survey (NHIS): Adult alternative health/complementary and alternative medicine. ftp://ftp.cdc.gov/pub/Health_Statistics/NCHS/ Survey_Questionnaires/NHIS/2007/English/. Accessed May 9, 2014. 17. IBM Corp. Released 2015. IBM SPSS statistics for windows, Version 23.0. Armonk, NY: IBM Corp.

18. Welna EM, Hadsall RS, Schommer JC. Pharmacists' personal use, professional practice behaviors, and perceptions regarding herbal and other natural products. J Am Pharm Assoc. 2003;43(5):602-611. 19. Tiralongo E, Wallis M. Attitudes and perceptions of Australian pharmacy students towards Complementary and Alternative Medicine - a pilot study. BMC Complement Altern Med. 2008;28(8):2. 20. Harris IM, Kingston RL, Rodrgiuez R, Choudary V. Attitudes towards complementary and alternative medicine among pharmacy faculty and students. Am J Pharm Educ. 2006;70(6):Article 129. 21. Shah B, Siganga W, Mallya U, et al. Pharmacy student perspectives on classroom education about herbal supplements. Am J Pharm Educ. 2005;69(5):Article 102.

22. Kwan D, Hirschkorn K, Boon H. US and Canadian pharmacists' attitudes, knowledge, and professional practice behaviors toward dietary supplements: a systematic review. BMC Complement Altern Med. 2006;6:31

23. Clauson KA, McQueen CE, Shields KM, Bryant PJ. Knowledge and attitudes of pharmacists in Missouri regarding natural products. Am J Pharm Educ. 2003;67(2):Article 41.

24. Kemper KJ, Amata-Kynvi A, Dvorkin L, et al. Herbs and other dietary supplements: healthcare professionals' knowledge, attitudes, and practices. Altern Ther Health Med. 2003;9(3):42-9.

25. Farina EK, Austin KG, Lieberman HR. Concomitant dietary supplement and prescription medication use is prevalent among US adults with doctor-informed medical conditions. J Acad Nutr Diet. 2014;114(11):1784-1790.

26. Food and Drug Administration (FDA). Medication Health Fraud. Published March 14, 2016. http://www.fda.gov/Drugs/

ResourcesForYou/Consumers/BuyingUsingMedicineSafely/ MedicationHealthFraud/default.htm Accessed April 28, 2016. 27. Venhuis B, Keizers P, van Riel A, de Kaste D. A cocktail of synthetic stimulants found in a dietary supplement associated with serious adverse events. Drug Test Analysis. 2014;6:578-581. 28. Mackowiak ED, Parikh A, Feely J. Herbal product evaluation in United States Pharmacy schools: core or elective program. Am J Pharm Educ. 2001;65(1):1-6.

29. Shields KM, McQueen CE, Bryant PJ. Natural product education in schools of pharmacy in the United States. Am J Pharm Educ. 2003;67(1):Article 10.

30. Lee MY, Benn R, Wimsatt L, et al. Integrating complementary and alternative medicine instruction into health professions education: organizational and instructional strategies. Acad Med. 2007;82(10):939-945. 


\section{American Journal of Pharmaceutical Education 2017; 81 (5) Article 92.}

31. Miller LG, Hume A, Harris IM, et al. White paper on herbal products. American College of Clinical Pharmacy.

Pharmacotherapy. 2000; 20(7):877-891.

32. Accreditation Council for Pharmacy Education. Accreditation standards and key elements for the professional program in pharmacy leading to the doctor of pharmacy degree (standards 2016). Published February 2, 2015. https://www.acpe-accredit.org/pdf/ Standards2016FINAL.pdf Accessed April 22, 2016.

33. Bonafede M, Caron W, Zeolla M. An evidence-based elective on dietary supplements. Am J Pharm Educ. 2009;73(5):Article 80.

34. Atayee RS, Singh RF, Best BM, et al. An active learning

assignment involving peer-to-peer presentations to improve pharmacy students' attitudes and knowledge of dietary supplements. Am J Pharm Educ. 2012;76(6):Article 113.

35. Noureldin M, Murawski MM, Mason HL, Plake KS. Student pharmacists' attitudes toward complementary and alternative medicine. J Am Pharm Assoc. 2013;53(6):618-625.

36. Howard N, Tsourounis C, Kapusnik-Uner J. Dietary supplement survey of pharmacists: personal and professional practices. $J$ Altern Complement Med. 2001;7(6):667-680.

37. Lin HW, Pickard AS, Mahady GB, et al. An instrument to evaluate pharmacists; patient counseling on herbal and dietary supplements. Am J Pharm Educ. 2010;74(10): Article 192. 


\section{American Journal of Pharmaceutical Education 2017; 81 (5) Article 92.}

Appendix 1. Questionnaire: Use of Herbal Supplements

Questions on herbal supplement use

In this section, we are asking about the use of herbal and dietary supplements. People take herbal and other non-vitamin dietary supplements for a variety of reasons. By herbal supplement, we mean herbs in the form of tablets or capsules that have been labeled as a dietary supplement. This does NOT include drinking herbal or green tea.

1. For each herbal supplement listed, indicate if you have ever used it, used it within the past 30 days, or used it in the past year by marking an " $X$ " in the appropriate column. If you took combination product, respond based on the primary ingredient in the product.

If you have never taken any of the listed herbal supplements below, proceed to Question 7.

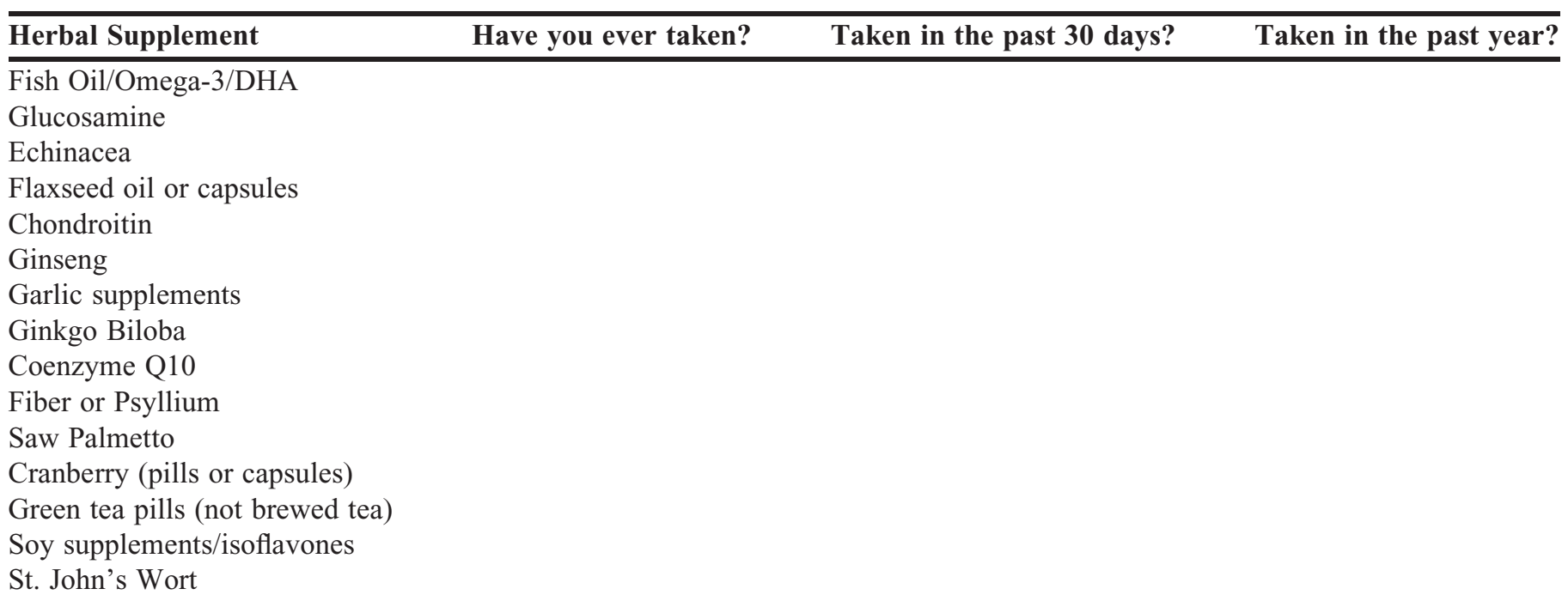

2. If you took the herbal supplement(s) for general health or wellness, select from the list below the reason(s), why you took them. Please check all that apply.

$\square$ Prescription or over-the-counter drugs are too expensive

$\square$ To treat or cure a specific disease or health problem

$\square$ To prevent a specific disease or health problem

$\square$ To improve physical performance

$\square$ To improve sports performance

$\square$ To improve immune system function

$\square$ To improve sexual performance

$\square$ To improve mental ability or memory

$\square$ Because medical treatments did not help

$\square$ Because medical treatments were too expensive

$\square$ It was recommended by a health care provider

$\square$ It was recommended by family, friends, or co-workers

3. If you used herbal or dietary supplement(s) to treat a medical condition(s), identify the condition it was used to treat in the table below. List the supplement used in the second column, and check your assessment of whether it was effective or not effective, in the last column.

Medical conditions treated with herbal or dietary supplements
How effective was the herbal supplement for treating the condition? (check effective or not effective)

Head or chest cold

Stomach or Intestinal illness 


\section{American Journal of Pharmaceutical Education 2017; 81 (5) Article 92.}

(Continued)

\begin{tabular}{|c|c|c|c|}
\hline \multirow{2}{*}{$\begin{array}{l}\text { Medical conditions treated } \\
\text { with herbal or dietary } \\
\text { supplements }\end{array}$} & \multirow[b]{2}{*}{ Herbal supplement used } & \multicolumn{2}{|c|}{$\begin{array}{l}\text { How effective was the herbal supplement } \\
\text { for treating the condition? (check effective } \\
\text { or not effective) }\end{array}$} \\
\hline & & Effective & Not Effective \\
\hline $\begin{array}{l}\text { Arthritis, Gout, Lupus, or Fibromyalgia } \\
\text { Joint pain or stiffness } \\
\text { Anxiety/Depression } \\
\text { Insomnia or trouble sleeping } \\
\text { Back pain or problem } \\
\text { Severe headache or migraine } \\
\text { Other medical conditions, not listed above }\end{array}$ & & & \\
\hline
\end{tabular}

4. Did you experience any side effects from any of the herbal supplements?
$\square$ YES
$\square \mathrm{NO}$

If YES please list the supplement name and the side effect below.

$\begin{array}{ll}\text { Supplement name: } & \text { Side effect } \\ \text { Supplement name: } & \text { Side effect } \\ \text { Supplement name: } & \text { Side effect }\end{array}$

5. Did you go to see a medical practitioner about any of these side effects?
$\square$ YES
$\square \mathrm{NO}$
$\square$ DON'T KNOW

6. Did you seek treatment in an emergency room for any of these side effects?
$\square$ YES
$\square \mathrm{NO}$
$\square$ DON'T KNOW

7. Would you recommend any of the above herbal or dietary supplements to your friends or family?

$\square$ YES
$\square$ NO

8. Would you recommend any of the above herbal or dietary supplements to your patients?

$\square$ YES
$\square$ NO
$\square$ NOT APPLICABLE

9. If you have never used any herbal or dietary supplement please select all the reason(s) that apply. If you have used any of the supplements listed above, proceed to next question.

$\square$ Never heard of it/ don't know much about it

$\square$ Never thought about it

$\square$ No reason

$\square$ Don't need it

$\square$ Don't believe in it/ It doesn't work

$\square$ It costs too much

$\square$ It is not safe to use

$\square$ A health care provider told me not to use it

$\square$ Medical science has not shown that it works

$\square$ Other 


\section{American Journal of Pharmaceutical Education 2017; 81 (5) Article 92.}

This section of the questionnaire asks you some questions about your knowledge of herbal supplements.

10. What sources of information do you use to determine whether or not you want to use herbal or dietary supplements? (Check all that apply)

$\square$ Labels on product containers

$\square$ Journals/professional newsletters

$\square$ Educational programs

$\square$ Textbooks

$\square$ Databases (eg, Natural Standard Database or Natural Medicine Comprehensive Database)

$\square$ Lecture material from classes

$\square$ Consulting health food stores

$\square$ Reports of clinical randomized trials

$\square$ Reports of systematic reviews or meta-analyses

11. Have you ever used government sources to obtain information about dietary supplements, eg, information from the National Institutes of Health and PubMed Dietary Supplement subset.

$\square$ YES

$\square$ NO

12. The FDA requires that dietary supplements be proven to be safe and effective before they are marketed.

$\square$ TRUE

$\square$ FALSE

13. The FDA must monitor the safety of dietary supplements once they are on the market.

$\square$ TRUE

FALSE

14. Match the adverse reaction to the appropriate dietary supplement by writing the letter in the blank.
Ephedra
a. Mood alteration/allergic reactions
Ginkgo Biloba
b. Arrhythmias/myocardial infarction
St. John's Wort
c. Bleeding
Echinacea
d. Nausea, vomiting, diarrhea, anorexia

15. Match each dietary supplement with its claimed health benefit

Fish oil

a. depression

Ginkgo Biloba

b. energy

Glucosamine

c. prostate disease

Saw palmetto

d. anti-inflammatory

Ephedra $\quad$ e. heart health

Ginger f. weight loss

Ginseng

g. joint health

St. John's Wort

h. mental function

This section of the questionnaire asks you some questions about your attitudes toward the use of herbal and dietary supplements.

16. How much do labels on herbal and dietary supplements help you understand if it is the right supplement for you?

Not at all $\begin{array}{lllllllll}0 & 1 & 2 & 3 & 4 & 5 & \text { A great deal }\end{array}$

17. How would you rate the amount of research conducted on dietary supplements?

Not at all $\quad 0 \quad 1 \quad 2 \quad 2 \quad 3 \quad 4 \quad 5$ Completely

Adequate Adequate

18. How essential are dietary supplements to your health?

Not at all $\quad 0 \quad 1 \quad 2 \quad 3 \quad 4 \quad 5$ Very Essential

Essential

19. How important is it to have a basic understanding/knowledge about herbal and dietary supplements before using them? Not at all $\quad 0 \quad 1 \quad 2 \quad 3 \quad 4 \quad 5$ Very Important

Important 


\section{American Journal of Pharmaceutical Education 2017; 81 (5) Article 92.}

20. How would you rate the amount of education offered to students at the College of Pharmacy on dietary and herbal supplements?

Not at all $\quad 0 \begin{array}{lllllll} & 1 & 2 & 3 & 4 & 5 & \text { Completely }\end{array}$

Adequate Adequate

This section of the questionnaire asks about your personal demographics and work experience.

21. Your age is:
$\square$ 18-25
$\square 26-35$
$\square 36-65$
$\square>65$

22. Your gender is:

$\square$ Female

$\square$ Male

23. Please check the pharmacy settings where you have worked as an intern or technician. Check all that apply. $\square$ Community pharmacy (chain)

$\square$ Long-term Care Pharmacy

$\square$ Community pharmacy (Independent)

$\square$ Hospital Pharmacy (out-patient)

$\square$ Hospital Pharmacy (In-patient)

$\square$ Managed Care Pharmacy

$\square$ Other

24. Did any of the practice sites where you worked sell herbal or dietary supplements?

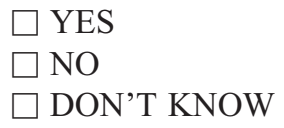

25. Have you ever counseled patients on the use of herbal or dietary supplements?

$\square$ YES

$\square \mathrm{NO}$

26. What year of pharmacy school are you? (Circle your class year)

2015201620172018

27. Your race is:

$\square$ White

$\square$ Non-white

28. Your ethnicity is:

$\square$ Hispanic

$\square$ Non-Hispanic

29. The main reason I DO or DO NOT take herbal and dietary supplements is: 